\title{
Therapeutic role of recurrent ESR1- CCDC170 gene fusions in breast cancer endocrine resistance
}

Li Li ${ }^{1,2,3,4}$, Ling Lin 1,2,3, Jamunarani Veeraraghavan ${ }^{5,6,7,8}$, Yiheng $\mathrm{Hu}^{1,2,3,5,6,7}$, Xian Wang ${ }^{1,2,3,5,6,7}$, Sanghoon Lee ${ }^{1,9}$, Ying $\operatorname{Tan}^{5,6,7}$, Rachel Schiff5,6,7,8 and Xiao-Song Wang ${ }^{1,2,3,5,6,7,8,9^{*}}$

\begin{abstract}
Background: Endocrine therapy is the most common treatment for estrogen receptor (ER)-positive breast cancer, but its effectiveness is limited by high rates of primary and acquired resistance. There are likely many genetic causes, and recent studies suggest the important role of ESR1 mutations and fusions in endocrine resistance. Previously, we reported a recurrent ESR1 fusion called ESR1-CCDC170 in 6-8\% of the luminal B breast cancers that has a worse clinical outcome after endocrine therapy. Despite being the most frequent ESR1 fusion, its functional role in endocrine resistance has not been studied in vivo, and the engaged mechanism and therapeutic relevance remain uncharacterized.
\end{abstract}

Methods: The endocrine sensitivities of HCC1428 or T47D breast cancer cells following genetic perturbations of ESR1-CCDC170 were assessed using clonogenic assays and/or xenograft mouse models. The underlying mechanisms were investigated by reverse phase protein array, western blotting, immunoprecipitation, and bimolecular fluorescence complementation assays. The sensitivity of ESR1-CCDC170 expressing breast cancer cells to concomitant treatments of tamoxifen and HER/SRC inhibitors was assessed by clonogenic assays.

Results: Our results suggested that different ESR1-CCDC170 fusions endow different levels of reduced endocrine sensitivity in vivo, resulting in significant survival disadvantages. Further investigation revealed a novel mechanism that ESR1-CCDC170 binds to HER2/HER3/SRC and activates SRC/PI3K/AKT signaling. Silencing of ESR1-CCDC170 in the fusion-positive cell line, HCC1428, downregulates HER2/HER3, represses pSRC/pAKT, and improves endocrine sensitivity. More important, breast cancer cells expressing ectopic or endogenous ESR1-CCDC170 are highly sensitive to treatment regimens combining endocrine agents with the HER2 inhibitor lapatinib and/or the SRC inhibitor dasatinib.

Conclusion: ESR1-CCDC170 may endow breast cancer cell survival under endocrine therapy via maintaining/ activating HER2/HER3/SRC/AKT signaling which implies a potential therapeutic strategy for managing these fusion positive tumors.

Keywords: ESR1-CCDC170, Endocrine resistance, Luminal breast cancer, HER2, SRC

\footnotetext{
* Correspondence: xiaosongw@pitt.edu

${ }^{1}$ Hillman Cancer Center, University of Pittsburgh, Pittsburgh, PA 15232, USA

${ }^{2}$ Department of Pathology, University of Pittsburgh, Pittsburgh, PA 15261,

USA

Full list of author information is available at the end of the article
}

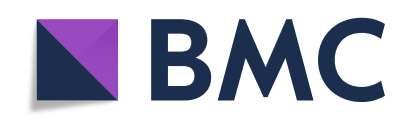

(c) The Author(s). 2020 Open Access This article is licensed under a Creative Commons Attribution 4.0 International License, which permits use, sharing, adaptation, distribution and reproduction in any medium or format, as long as you give appropriate credit to the original author(s) and the source, provide a link to the Creative Commons licence, and indicate if changes were made. The images or other third party material in this article are included in the article's Creative Commons licence, unless indicated otherwise in a credit line to the material. If material is not included in the article's Creative Commons licence and your intended use is not permitted by statutory regulation or exceeds the permitted use, you will need to obtain permission directly from the copyright holder. To view a copy of this licence, visit http://creativecommons.org/licenses/by/4.0/ The Creative Commons Public Domain Dedication waiver (http://creativecommons.org/publicdomain/zero/1.0/) applies to the data made available in this article, unless otherwise stated in a credit line to the data. 


\section{Background}

Endocrine therapy is the most effective treatment for estrogen-receptor (ER)-positive breast cancer (also known as luminal breast cancer). Agents targeting ER, including selective ER modulators (SERMs, i.e., tamoxifen), selective ER downregulators (SERDs, i.e., fulvestrant), and aromatase inhibitors (AIs, i.e., letrozole), are the mainstays of treatment [1]. However, the efficacy of endocrine therapy is limited by intrinsic and acquired endocrine resistance [2]. About a quarter of the patients with primary tumor and almost all patients with metastases will present with or eventually develop endocrine resistance [3]. Tremendous efforts have been made to study the mechanism of endocrine resistance, and emerging evidence suggests that ESR1 mutations or fusions that mutate or eliminate its ligand binding domain constitute one of the most important driving mechanisms [3-6].

Recurrent gene fusions resulting from chromosome translocations are a critical class of genetic aberrations causing cancer [7], which have fueled modern cancer therapeutics. Recently, several milestone studies have identified recurrent gene fusions in different types of solid tumors with tremendous clinical impact. This is represented by the discovery of EML4-ALK fusion in $\sim 4 \%$ of non-small cell lung cancer and FGFR-TACC fusion in $3 \%$ of glioblastomas that have culminated in effective targeted therapies in these tumors [8, 9]. In particular, the discovery of EML4-ALK has led to accelerated approval of several ALK inhibitors by the U.S. Food and Drug Administration (FDA) for the treatment of non-small cell lung cancer with stunning clinical responses [8]. Most recently, FDA granted accelerated approval to the first pan-cancer drug for the treatment of solid tumors, larotrectinib, against the NTRK gene fusions [10]. Characterizing the role of gene fusions in breast cancer, particularly in endocrine resistance, will be critical for developing new and effective targeted therapies.

ER-positive breast cancers can be classified into "luminal A" and "luminal B" subtypes. The luminal B breast tumors are more aggressive and endocrine-resistant luminal breast cancers that have high proliferative activity by Ki-67 index. Luminal B breast cancer accounts for $15-20 \%$ of all breast cancers [11] and is the most common subtype in young women [12]. In our previous study, through large-scale analyses of RNA-seq data from The Cancer Genome Atlas, we identified recurrent gene rearrangements between ESR1 and its neighboring gene, coiled-coil domain containing 170 (CCDC170), in $6-8 \%$ of luminal B breast cancer, the majority of which are likely the result of tandem duplications [13]. Wildtype CCDC170 belongs to the structural maintenance of chromosome (SMC) protein family that maintains chromosome conformation through SMC-dependent looping and microtubule stabilization during interphase and mitosis [14, 15]. The ESR1-CCDC170 fusions join the $5^{\prime}$ untranslated region of ESR1 to the coding region of CCDC170, generating N-terminally truncated CCDC170 proteins ( $\triangle \mathrm{CCDC170)}$ expressed under the ESR1 promoter (Additional file 1: Fig. S1). This structure is distinct from other ESR1 fusions that retain its transcriptional activation domain [6]. When introduced into breast cancer cells, ESR1-CCDC170 proteins enhance ligand-independent growth factor signaling, leading to increased cell aggressiveness and tumorigenesis [13]. To date, ESR1-CCDC170 remains the most frequent gene fusion detected in luminal B breast cancer, and its recurrence has been subsequently supported by several recent studies [5, 16-19]. In addition, this fusion is also detected as a recurrent event in ovarian cancer, and its presence has been associated with exceptional shortterm survival [20]. More interestingly, a recent publication reported the association of ESR1-CCDC170 fusions with lack of response to neoadjuvant letrozole treatment [17]. Nonetheless, detailed functional evidence demonstrating the role of ESR1-CCDC170 in endocrine resistance especially in the in vivo context and the precise mechanism for this fusion to endow ligand-independent growth factor signaling has been lacking, which is not addressed in our previous study or the following reports. Furthermore, the therapeutic strategies to treat ESR1-CCDC170-positive tumors are ill-understood. Here, we provide detailed evidence supporting the function of ESR1-CCDC170 in endowing breast cancer cell survival and reducing endocrine sensitivity in vitro and in vivo and unravel its novel action mechanism via modulating and activating the SRC/HER2/HER3 complex. Our study suggests the combination of inhibitors against these kinases with tamoxifen treatment as a potential new therapeutic strategy for breast tumors harboring ESR1-CCDC170 fusions.

\section{Materials and methods \\ Cell culture}

$\mathrm{ER}^{+}$breast cancer cell lines T47D, HCC1428, and ZR75-1 were purchased from American Type Culture Collection, cultured in RPMI-1640 (Corning) supplemented with $10 \%$ fetal bovine serum (Hyclone). For estrogen deprivation, cells were cultured in phenol red-free RPMI 1640 (Invitrogen) supplemented with 5\% charcoaldextran-stripped serum (Sigma).

\section{Engineering ectopic overexpression models}

Lentiviral constructs and the lentivirus for ectopic expression of ESR1-CCDC170 fusion variants and wtCCDC170 were from our previous study [13]. The T47D cells were infected with lentivirus containing these constructs in medium containing $4 \mu \mathrm{g} / \mathrm{ml}$ polybrene. Medium was replaced after overnight incubation. The 
cells with high GFP reporter expression were selected using flow cytometry 2 days later.

\section{Antibodies and reagents}

Primary antibodies against pEGFR-Y1068 (D7A5), EGFR, pHER2-Y877, pHER2-Y1221/1222 (6B12), pHER2-Y1248, HER2/ErbB2 (D8F12), pHER3-Y1289 (D1B5), HER3 (D22C5), pMet-Y1234/1235 (D26), Met (D1C2), pERS118 $\alpha$ (16 J4), pER $\alpha$-S167 (D1A3), ER $\alpha$ (D8H8), pAKTS473 (D9E), AKT (C67E7), pERK (137F5), ERK (D13E1), pSrc-S416 (D49G4), Src (32G6), Integrin $\beta 1(D 2 E 5)$, and Bcl-2 were purchased from Cell Signaling Technology. GFP antibody and HER2/neu Ab-8 (Clone e2-4001) mouse monoclonal antibody used for IP were obtained from Thermo Fisher. C6orf97 antibody is from GeneTex, V5 (MA5-15253) antibody is from Thermo Fisher, and (Z)-4Hydroxytamoxifen is from Sigma. Fulvestrant (ICI-182780, ZD 9238), lapatinib (GW572016), dasatinib, BEZ235, and AZD8931 were purchased from Selleckchem. Drugs were resolved in DMSO, diluted in culture medium before use.

\section{In vivo xenograft experiments}

All animal experiments were performed in accordance with the institutional guidelines and regulations, and the animal protocol was approved by the BCM Institutional Animal Care and Use Committee (Approval \# AN-6123). Briefly, $1 \times 10^{7}$ T47D cells ectopically expressing the empty vector or the $\triangle \mathrm{CCDC170}$ fusion variants E2-E7 and E2-E10 were resuspended in 20\% Matrigel solution and injected bilaterally into 4-6-week-old female athymic nude mice (Harlan Sprague-Dawley), supplemented with 60-day-release 17 $\beta$-estradiol pellets. Xenograft tumors of the T47D models were successfully engrafted in 6-9 mice per group. Growth of the xenograft tumors was monitored twice per week, and tumor volume was measured using the formula $1 / 2$ (length $\times$ width $\left.^{2}\right)$. When the tumors reached $200 \mathrm{~mm}^{3}$, mice with tumors expressing the empty vector, E2-E7, or E2-E10 variants were randomized to +/tamoxifen treatment. Tamoxifen $(25 \mu \mathrm{g} / \mathrm{kg}$ body weight) was injected subcutaneously for 5 days/week. Growth of the xenograft tumors was monitored twice per week until the end of the experiment.

\section{siRNA and transfection}

The E2-E10-specific siRNA (5'-CAUCACUGAG AUUAAAACU-3'), ER $\alpha$-specific siRNA (5'-AGGCUC AUUCCAGCCACAGTT-3'), HER2-specific siRNA-1 (L003126-00, ON-TARGETplus Human ERBB2 siRNA SMARTPool), HER2-specific siRNA-2 (5'-CACGUU UGAGUCCAUGCCCAA-3'), Src-specific siRNA-1 (J003175-15, 5'-CCAAGGGCCUCAACGUGAA-3'), and Src-specific siRNA-2 (J-003175-16, 5'-GGGAGAACCU CUAGGCACA-3') and control siRNA (D-001810-10-50, ON-TARGETplus Non-targeting Pool) were purchased from Dharmacon. All siRNAs were transfected using Lipofectamine RNAi MAX Reagent (Invitrogen) according to manufacturer's instructions.

\section{Reverse phase protein array analysis}

Reverse phase protein array assay was performed as described previously [21]. Briefly, protein lysates were prepared from HCC1428 cells with control or E2-E10 siRNA knockdown using modified Tissue Protein Extraction Reagent (TPER) (Pierce) and a cocktail of protease and phosphatase inhibitors (Roche Life Science). The protein lysates were then diluted into $0.5 \mathrm{mg} / \mathrm{ml}$ of total protein in SDS sample buffer and denatured on the same day. For each spot on the array, the backgroundsubtracted foreground signal intensity was subtracted by the corresponding signal intensity of the negative control slide (omission of primary antibody) and then normalized to the corresponding signal intensity of total protein for that spot. The median of the triplicate experimental values (normalized signal intensity) is taken for each sample for subsequent statistical analysis.

\section{Protein subcellular localization}

Fractionation of the nuclear and cytoplasmic proteins from T47D cells ectopically overexpressing the empty vector, wtCCDC170, or the $\triangle \mathrm{CCDC170}$ fusion variants E2-E7 or E2-E10 was performed using the NE-PER Nuclear and Cytoplasmic Extraction Kit (Thermo Fisher) according to manufacturer's instructions. The fractionated protein samples $(30 \mu \mathrm{g}$ protein) were then analyzed by western blot, as previously described [13].

\section{Immunoprecipitation}

For IP with HER2/HER3/Src antibody, as described previously [22], cells were harvested and lysed in NETN400 buffer (50 mM Tris- $\mathrm{HCl}, \mathrm{pH} 8.0,400 \mathrm{mM} \mathrm{NaCl}, 1$ mM EDTA, and $0.5 \%$ Nonidet P-40) for $25 \mathrm{~min}$ on ice. The samples were centrifuged at 13,000 rpm for $15 \mathrm{~min}$, and the supernatants were diluted with the same buffer without $\mathrm{NaCl}(\mathrm{NETN}-0)$ to obtain a final concentration of $\mathrm{NaCl}$ at $150 \mathrm{mM}$. The samples were incubated with the appropriate antibodies at $4{ }^{\circ} \mathrm{C}$ with rocking for $2 \mathrm{~h}$. Protein $\mathrm{G}$ agarose was then added, and the incubation was continued for an additional $2 \mathrm{~h}$. Beads were then washed three times using the NETN-150 buffer. The bound proteins were eluted with $100 \mathrm{mM}$ glycine, $\mathrm{pH}$ 2.5 , and then neutralized by adding $1 / 10 \mathrm{vol}$ of $1 \mathrm{M}$ Tris$\mathrm{Cl}, \mathrm{pH}$ 8.0. Eluted proteins were separated on $4-12 \%$ SDS-PAGE and blotted with the corresponding antibodies as indicated.

\section{Clonogenic assay}

T47D cells were cultured in normal medium, RPMI1640 with phenol red and $10 \%$ FBS, and seeded at a density of 
5000 cells per well in 24/48-well plate. After $24 \mathrm{~h}$, medium was changed to ED medium, phenol red-free RPMI1640 supplemented with 5\% charcoal-stripped serum (CSS), with or without indicated drugs in the presence or absence of siRNAs, for 14 days. For HCC1428, cells were seeded at a density of 5000 or 10 , 000 cells per well in 24-well plate, with the indicated drugs added $24 \mathrm{~h}$ later, and the cells were then cultured for another 13 to 18 days. After that, the cells were fixed and stained with crystal violet; the colonies formed were calculated as intensity by using Image software (National Institutes of Health) with ColonyArea plugin.

\section{Statistical analysis}

The results of all in vitro experiments were compared by Student's $t$ tests or two-way ANOVA, and all data are shown as mean \pm standard deviation. For the in vivo study, statistical comparisons of tumor growth rates were performed using two-way mixed ANOVA that takes account of mice groups and time points as factors and mouse subjects as random effects [23-25]. Longterm outcomes were evaluated by survival analysis methods. "Events" were defined to mimic clinically relevant outcomes; time to tumor regression (tumor-volume-halving) was analyzed using Kaplan-Meier survival curves and compared by the generalized Wilcoxon test.

\section{Results}

\section{ESR1-CCDC170 fusions endow reduced endocrine} sensitivity in vitro and in vivo

To explore the role of different forms of ESR1-CCDC170 fusions in endocrine resistance, we engineered four major fusion variants, E2-E6, E2-E7, E2-E8 and E2-E10, that join the exon 2 of ESR1 with the exon 6, 7, 8, or 10 of $C C D C 170$, respectively, into the T47D luminal breast cancer cells known to be dependent on estrogen [26]. These fusion variants encode different sizes of N-terminally truncated CCDC170 ( $\triangle \mathrm{CCDC170)}$ proteins, which were verified by western blotting (Additional file 2: Fig. S2). To explore its role in endocrine resistance, we assessed the consequences of ESR1-CCDC170 ectopic expression on the outcome of tamoxifen treatment in vivo. T47D xenograft tumors expressing vector, E2-E7, or E2-E10 fusion variants were developed in female athymic nude mice, implanted with estradiol (E2) pellets. When the tumors reached $150-200 \mathrm{~mm}^{3}$, the mice were randomized into tamoxifen treatment $(25 \mu \mathrm{g} / \mathrm{kg}$ body weight) and untreated groups. In the absence of tamoxifen, tumor growth rates were significantly increased in the xenografts expressing E2-E10 fusion $(P=0.001)$ and to a lesser degree in the xenografts expressing E2-E7 fusion $(P=0.069$, Fig. 1a, b). When treated with tamoxifen, the vector group showed true tumor regression with $51 \%$ decrease in size ( $P=0.000007$ comparing $+/$-tamoxifen), whereas the E2-
E7 expressing tumors sustained steady tumor volumes with only $14 \%$ decrease in size $(P=0.003$ comparing +/-tamoxifen). The E2-E10 expressing tumors continued to grow and then stabilized at higher tumor burdens, with almost a twofold increase in tumor volumes $(P=0.151$ comparing $+/$-tamoxifen). The relative endocrine resistance of ESR1-CCDC170 expressing tumors was evident when the tumor growth rates of different models within the tamoxifen-treated group are compared (vector vs E2E7: $P=0.001$, vector vs E2-E10: $P=0.000002$, Fig. $1 \mathrm{~b}$ ). Kaplan-Meier analysis revealed a significantly worse regression-free survival for both E2-E7 $(P<0.01)$ and E2E10 $(P<0.001)$-overexpressing tumors treated with tamoxifen compared to the vector control tumors (Fig. 1c). These data suggest that ESR1-CCDC170 variants render the T47D xenografts less sensitive to tamoxifen treatment in the in vivo context, and the E2-E7 and E2-E10 variants endow different levels of reduced responsivity.

Next, we assessed the effect of depleting ESR1CCDC170 on the endocrine sensitivity of HCC1428, an $\mathrm{ER}^{+}$breast cancer cell line harboring endogenous E2-E10 fusion. HCC1428 was derived from plural effusion of a 49-year-old patient with metastatic luminal breast carcinoma after chemotherapy, who died 6 months later [27]. Thus, this cell line is endocrine therapy-naive. We used a validated siRNA targeting the E2-E10 fusion junction that can specifically knockdown the E2-E10 fusion, as we previously reported [13], and the silencing of E2-E10 protein was validated by western blot (Additional file 3: Fig. S3A). The cells were then treated with 4-hydroxytamoxifen (4$\mathrm{OHT}$ ), the active metabolite of tamoxifen used for in vitro experiments, or fulvestrant, a second-line endocrine agent that act by degrading ER. Tamoxifen or fulvestrant alone reduced the cell growth efficiently, with E2-E10 depletion led to more significant reduction of cell growth compared to the siRNA control (esp. in fulvestrant-treated cells, Fig. 2a), suggesting that silencing E2-E10 increases endocrine responsiveness of HCC1428 cells.

\section{ESR1-CCDC170 fusions augment HER2/HER3/SRC/AKT pathway}

To gain insights into ESR1-CCDC170-driven mechanisms, we performed reverse phase protein array (RPPA) analysis in the HCC1428 cells with or without ESR1CCDC170 silencing, using about 200 validated antibodies against an array of cancer-related signaling molecules. Interestingly, ESR1-CCDC170 silencing leads to substantial repression of ER $\alpha, B C L 2, H E R 3$, and c-SRC protein levels as well as total/phospho-HER2 (Fig. 2b). We further validated these alterations by western blotting in E2-E10silenced HCC1428 cells treated with vehicle, tamoxifen or fulvestrant. The protein levels of HER2, HER3, and BCL2 were indeed repressed following E2-E10 depletion. However, we did not observe repression of ER $\alpha$ protein level. 


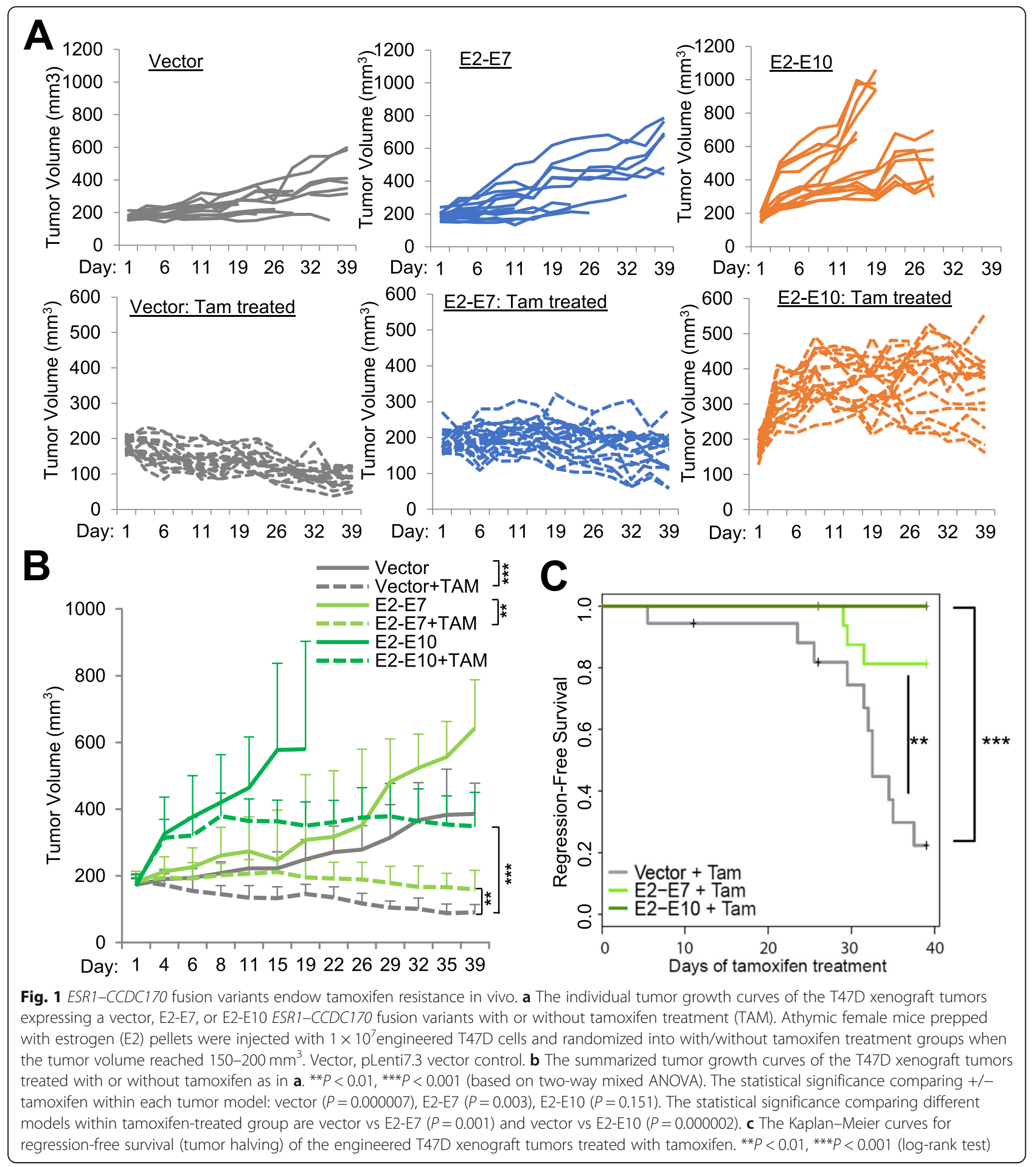

Interestingly, HER2 protein level, but not transcript level, was upregulated by both tamoxifen and fulvestrant treatment, while depletion of E2-E10 counteracted this effect, especially under fulvestrant treatment (Fig. 2c, Additional file 3: Fig. S3B). In addition, pSRC-Y416 and pAKT-S473 were repressed following E2-E10 silencing in HCC1428 cells. These data suggest that E2-E10 may sustain cell survival via maintaining
HER2/HER3 protein levels and activating SRC and AKT signaling in HCC1428 cells.

We then went on to assess the signaling alterations in T47D cells ectopically expressing ESR1-CCDC170 variants or wtCCDC170 following endocrine treatment. Interestingly, estrogen deprivation induced activation of pSRC-Y416, which was more potent in T47D expressing 


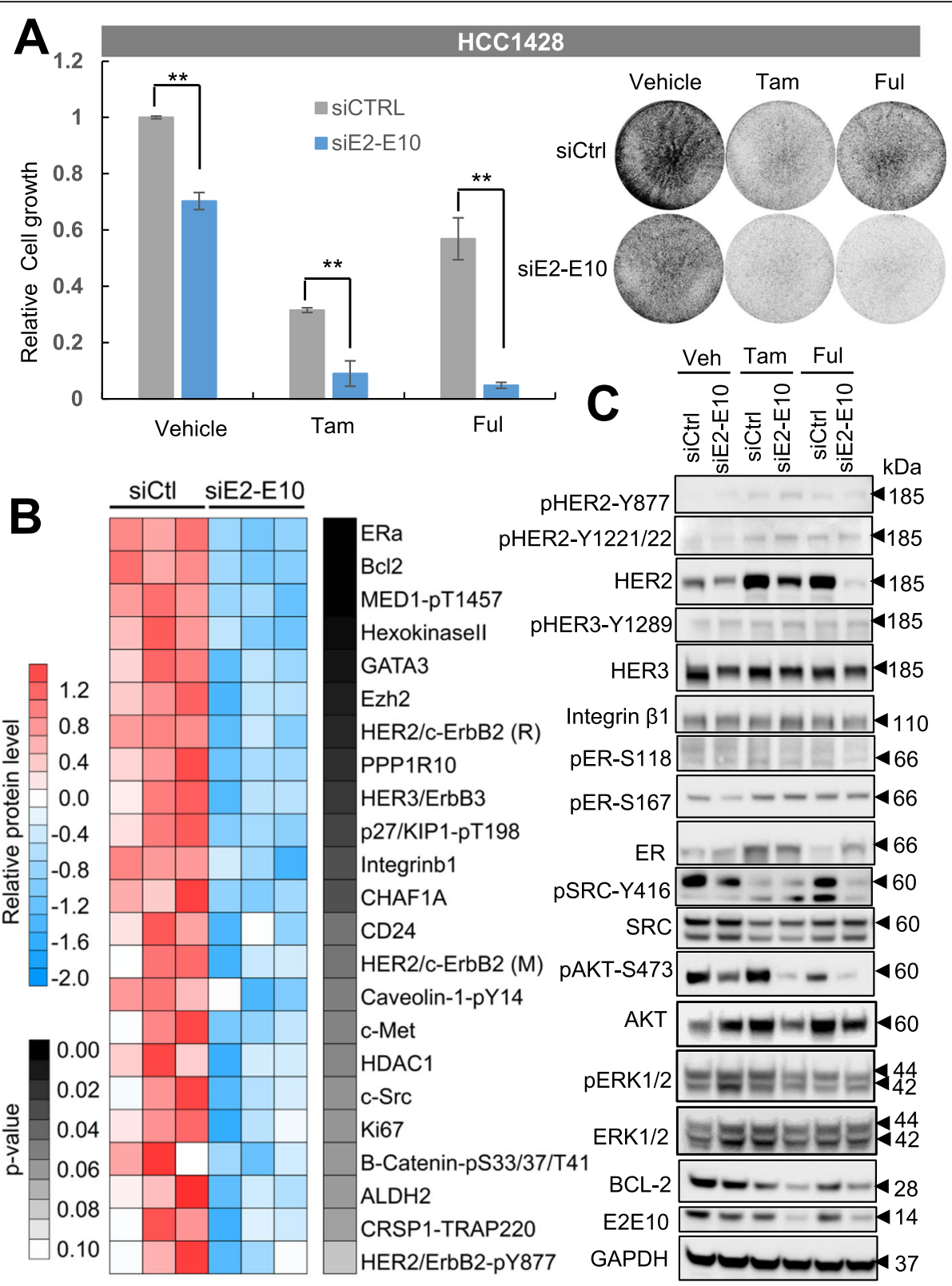

Fig. 2 Silencing of ESR1-CCDC170 increases the endocrine responsiveness of HCC1428 cells. a Silencing of the E2-E10 fusion in HCC1428 cells reduced cell viability as shown by clonogenic assays. Cells were first treated with siRNAs for 3 days in biological triplicates, and then treated with 4-hydroxytamoxifen (Tam, $0.5 \mu \mathrm{M})$ or fulvestrant (Ful, $0.1 \mu \mathrm{M})$ for $72 \mathrm{~h}$, together with the siRNAs simultaneously. The left chart shows the relative intensity of triplicates (means \pm SD) normalized to the cells treated with vehicle and scramble siRNA control (siCtrl). The western blots verifying the knockdown efficiency and the representative images of clonogenic assays are shown on the right. ${ }^{* *} P<0.01$; Student's $t$ test. Experiments performed at least three times. $\mathbf{b}$ Heatmap showing the top downregulated $(P<0.1)$ signaling molecules in E2-E10-silenced HCC1428 cells revealed by RPPA data. HER2/c-ErbB2 (R) and HER2/c-ErbB2 (M) indicate rabbit and mouse antibodies detecting the total HER2 protein respectively. c Protein extracts from the HCC1428 treated as in a were analyzed by western blot analysis of key signaling molecules revealed by RPPA

ESR1-CCDC170 variants compared to wtCCDC170 or vector control. Unlike pSRC-Y416, the activation of pHER3-Y1289 and pAKT-S473 were induced by estrogen deprivation in only E2-E8 or E2-E10 variant, respectively (Fig. 3a). When cells were treated with tamoxifen, increased total HER2/HER3 levels were observed in all engineered T47D cells. This is consistent with the previous report that tamoxifen can stimulate HER2/HER3 expression [28]. In addition, stronger activations of pHER2-Y1221/1222, pHER3-Y1289, pSRC416, and pAKT-S473 were observed in T47D cells expressing the fusion variants compared to wtCCDC170 


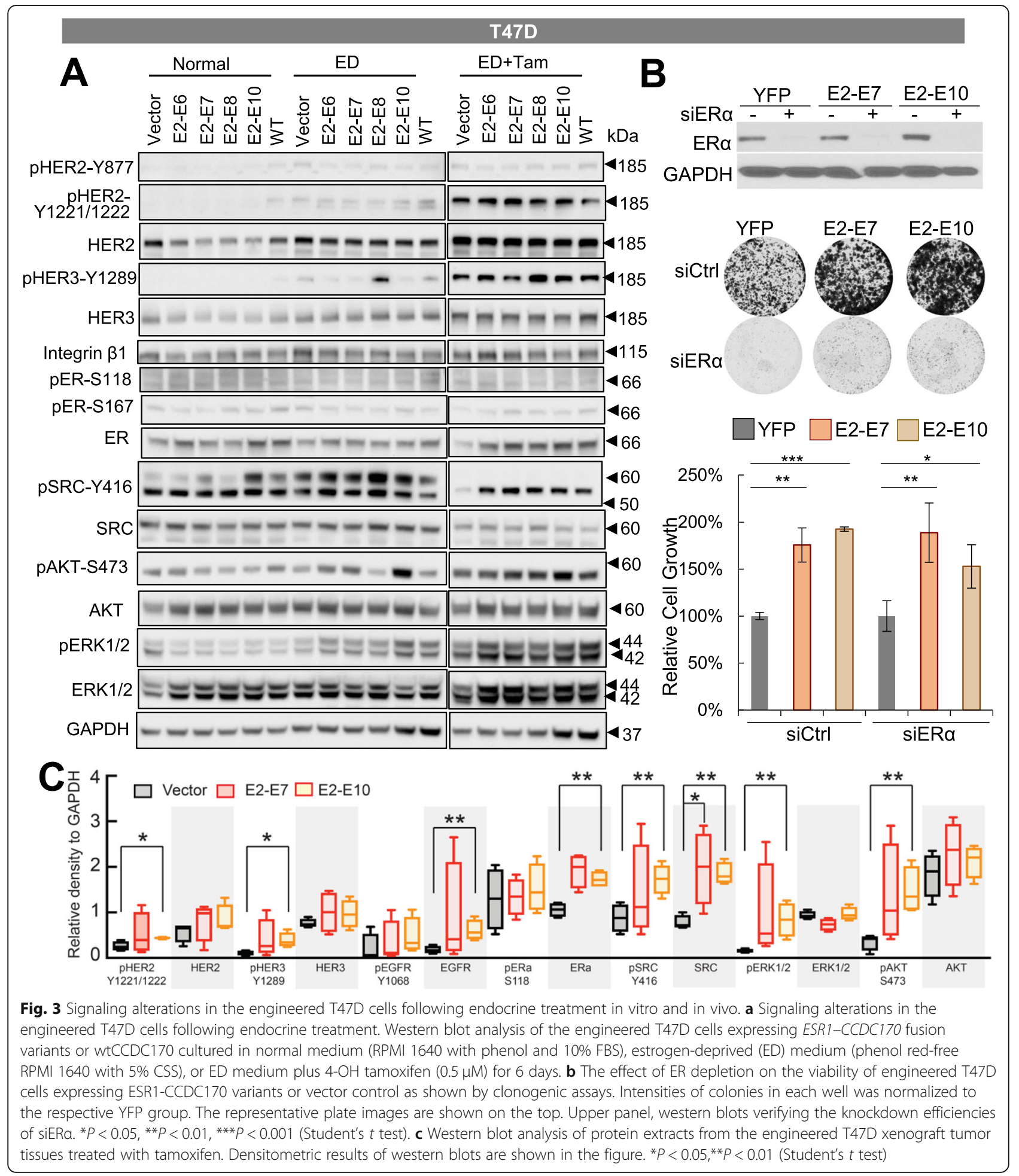

or vector control, suggesting that ESR1-CCDC170 fusions enhance the activation of HER2/HER3/SRC/ PI3K/AKT signaling under tamoxifen treatment. Similar significant signaling alternations including increased activation of HER2, HER3, SRC, AKT, and ERK and increased EGFR, SRC, and ER protein levels were observed following tamoxifen treatment in E2E10-expressing T47D xenograft tumors, and to a lesser degree in E2-E7-expressing tumors (Fig. 3c, Additional file 4: Fig. S4), consistent with their tumor growth curves shown in Fig. 1a, b. 
It is notable that the p-SRC-Y416 antibody detected two bands. The upper band that matches the predicted size of $60 \mathrm{kD}$ was diminished following tamoxifen treatment. SRC can be cleaved by calpain at $\mathrm{N}$-terminal unique domain [29], which generates a truncated Src of $52 \mathrm{kD}$, the size of the lower band. As calpain can be activated by endocrine treatment [30], it is possible that tamoxifen treatment may activate calpain, which then cleaves the $60 \mathrm{kD}$ SRC into a $52 \mathrm{kD}$ protein fragment. This suggests that the modulation of SRC under tamoxifen treatment is complicated, which requires further mechanism study to elucidate.

As many survival signaling pathways that drive endocrine resistance rely on modulating and reactivating ER $\alpha$ [31-33], we examined the effect of ESR1 depletion on the viability of engineered T47D cells expressing ESR1CCDC170 variants or vector control. Clonogenic assays suggested that while ER depletion effectively inhibited cancer cell viability, ESR1-CCDC170 significantly increased the survival of T47D cells. This implies possible ER-independent mechanism engaged by ESR1CCDC170 to endow cancer cell survival under endocrine therapy (Fig. 3b).

\section{ESR1-CCDC170 localizes to cytoplasm, associates with HER2/HER3/SRC, and forms homodimers}

Next, we asked whether ESR1-CCDC170 modulates the HER2/HER3/SRC pathway by forming complex with them. To test this, we performed immunoprecipitations using HER2, HER3, or SRC antibodies on the T47D cells ectopically expressing E2-E10 or wtCCDC170 and performed western blots using CCDC170 antibody. Interestingly, the $\triangle \mathrm{CCDC} 170$ protein encoded by E2E10 co-immunoprecipitated with endogenous HER2, HER3, and SRC (Fig. 4a), suggesting that E2-E10 forms complex with HER2, HER3, and SRC. On the other

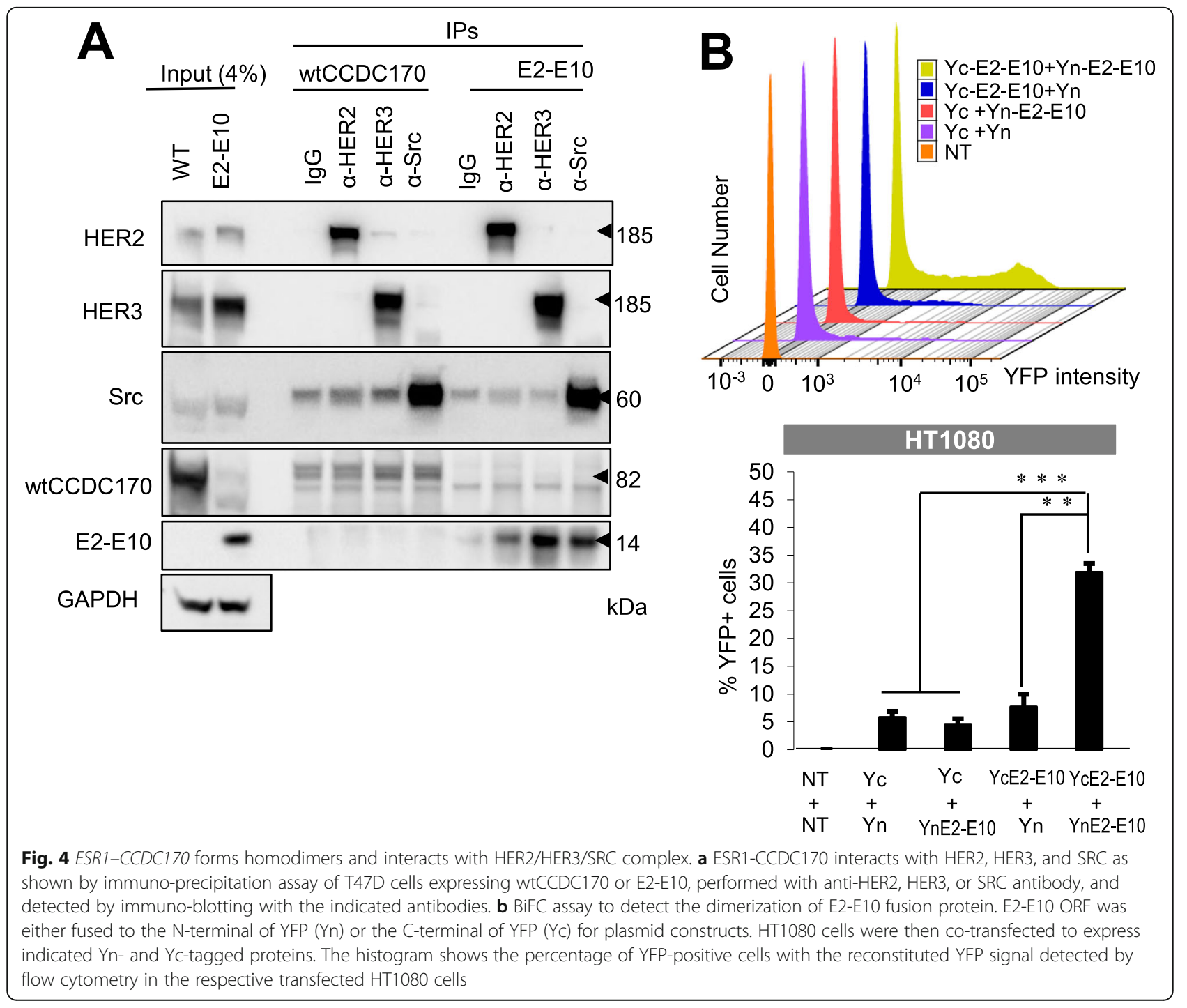


hand, only very modest wtCCDC170 protein bands were detected in the products immunoprecipitated with SRC/ HER3, suggesting that the fusion protein has a much higher binding affinity to this complex. The interaction between HER2 and $\triangle \mathrm{CCDC} 170$ was further verified on T47D cells ectopically expressing V5-E2-E7 or V5-E2E10 via immunoprecipitation using V5 antibody and western blots using HER2 antibody (Additional file 5: Fig. S5). Next, we examined the subcellular localizations of ectopically expressed ESR1-CCDC170 proteins which revealed that the $\triangle \mathrm{CCDC} 170$ proteins are more enriched in the cytoplasm, in contrast to the nuclear-enriched wtCCDC170 (Additional file 6: Fig. S6). Among the fusion variants, E2-E10 is mostly localized to cytoplasm, in line with its stronger effect on tamoxifen resistance.

We then investigated whether the $\mathrm{N}$-terminal truncated CCDC170 proteins encoded by ESR1-CCDC170 fusions form dimers, which we speculate may help stabilize the HER2/HER3/SRC complex. To test this, we performed bimolecular fluorescence complementation (BiFC) assay, which detects the proximity of two interacting proteins via reconstituted YFP fluorescence [34]. Here, we tested the E2-E10 variant that encodes the smallest $\triangle \mathrm{CCDC170}$ protein with most $\mathrm{N}$-terminal truncation. The E2-E10 open reading frame (ORF) was either fused to the $\mathrm{N}$ terminal fragment of YFP (Yn) or to the C-terminal fragment of YFP (Yc), and then introduced into HT1080 cells, which possess the lowest auto-fluorescence, thus is most suited for BiFC assay [34, 35]. Western blots using GFP antibodies that cross-identify the YFP portion of proteins verified that Yn- or Yc-tagged E2-E10 was expressed at comparable levels between different transfected HT1080 cells (Additional file 7: Fig. S7). The reconstituted YFP signal was only detectable in the cells co-transfected with Yn-E2-E10 and Yc-E2-E10, suggesting that E2-E10 forms homodimer (Fig. 4b).

\section{SRC and HER2 inhibitors increase tamoxifen sensitivity in} luminal breast cancer cells expressing ESR1-CCDC170

Next, we sought to test if targeting the HER or SRC signaling can revert the tamoxifen resistance driven by ESR1-CCDC170. We selected two drugs for this test, lapatinib, the first dual-specificity inhibitor targeting EGFR and HER-2 [36], and the FDA-approved SRC inhibitor, dasatinib $[37,38]$. We cultured the T47D cells ectopically expressing ESR1-CCDC170 fusion variants in estrogen-deprived condition and treated them either with tamoxifen alone or combined with lapatinib or dasatinib. Clonogenic assay results showed that when treated with tamoxifen, T47D cells overexpressing the ESR1-CCDC170 fusion variants grew more aggressively than that of the vector control and the wtCCDC170expressing T47D cells, suggesting that ESR1-CCDC170 fusion variants rendered T47D cells less dependent on estrogen (Fig. 5a). Further, the colony formations were significantly reduced when the cells were treated with tamoxifen plus lapatinib (Fig. 5a) or dasatinib (Fig. 5b) compared to tamoxifen treatment alone, with dasatinib showing much more potent sensitizing effects.

Next, we treated the HCC1428 cells expressing endogenous E2-E10 fusion with lapatinib, dasatinib, BEZ235 (PI3K/mTOR kinase inhibitor), or AZD8931 (a pan-ERBB inhibitor that inhibits EGFR, HER2, and HER3), in combination with tamoxifen or fulvestrant (Fig. 6). While all these inhibitors significantly inhibited cell viability compared to tamoxifen or fulvestrant treatment alone, lapatinib and dasatinib showed better therapeutic activities than BEZ235 or AZD8931. This suggests the importance of directly targeting SRC/HER2 to block fusion-driven signaling. In the presence of tamoxifen, dasatinib showed better activity than lapatinib (Fig. 6a), whereas when combined with fulvestrant, lapatinib and dasatinib showed comparable therapeutic effects. In addition, combining both lapatinib and dasatinib with fulvestrant resulted in additional therapeutic benefit which almost wiped out the cells (Fig. 6b). To verify the specific effect of HER2 or SRC inhibition in HCC1428 cells, we depleted HER2 or SRC using their specific siRNAs and treated the cells with tamoxifen or fulvestrant (Fig. 7a, b). The efficiency of these siRNAs was validated by western blots. Both HER2 and SRC silencing led to potent repression of cell viability especially when combined with fulvestrant treatment, similar to the effect of ESR1-CCDC170 silencing.

Next, we assessed the therapeutic effect of lapatinib and dasatinib in ZR-75-1 cells harboring the E2-E6 fusion [13]. ZR-75-1 is an endocrine therapy-naïve cell line derived from ascitic effusion of a 63-year-old metastatic breast cancer patient who was subsequently treated with tamoxifen without apparent benefit [39]. This cell line was excluded from genetic silencing study as the fusion variant expressed in this cell line is not amendable to design siRNAs against its fusion junction due to their general toxicity to the cells. However, this cell line could be useful to provide additional insights into the therapeutic values of HER2/SRC inhibition in fusion positive cancer cells. We thus treated the ZR-75-1 cells with increasing doses of tamoxifen or fulvestrant, in combination with lapatinib, dasatinib, or both (Additional file 8: Fig. S8AB). Our results showed that ZR-75-1 cells responded to both tamoxifen and fulvestrant treatment, with fulvestrant showing more potent effect. Concomitant lapatinib treatment resulted in further decreased cell viability compared to endocrine treatment alone, whereas dasatinib did not show any significant therapeutic benefit. Western blots revealed that the expression of SRC in ZR-75-1 cells appears to be at very low level (Additional file 9: Fig. S9). This suggests that the treatment strategy for managing 


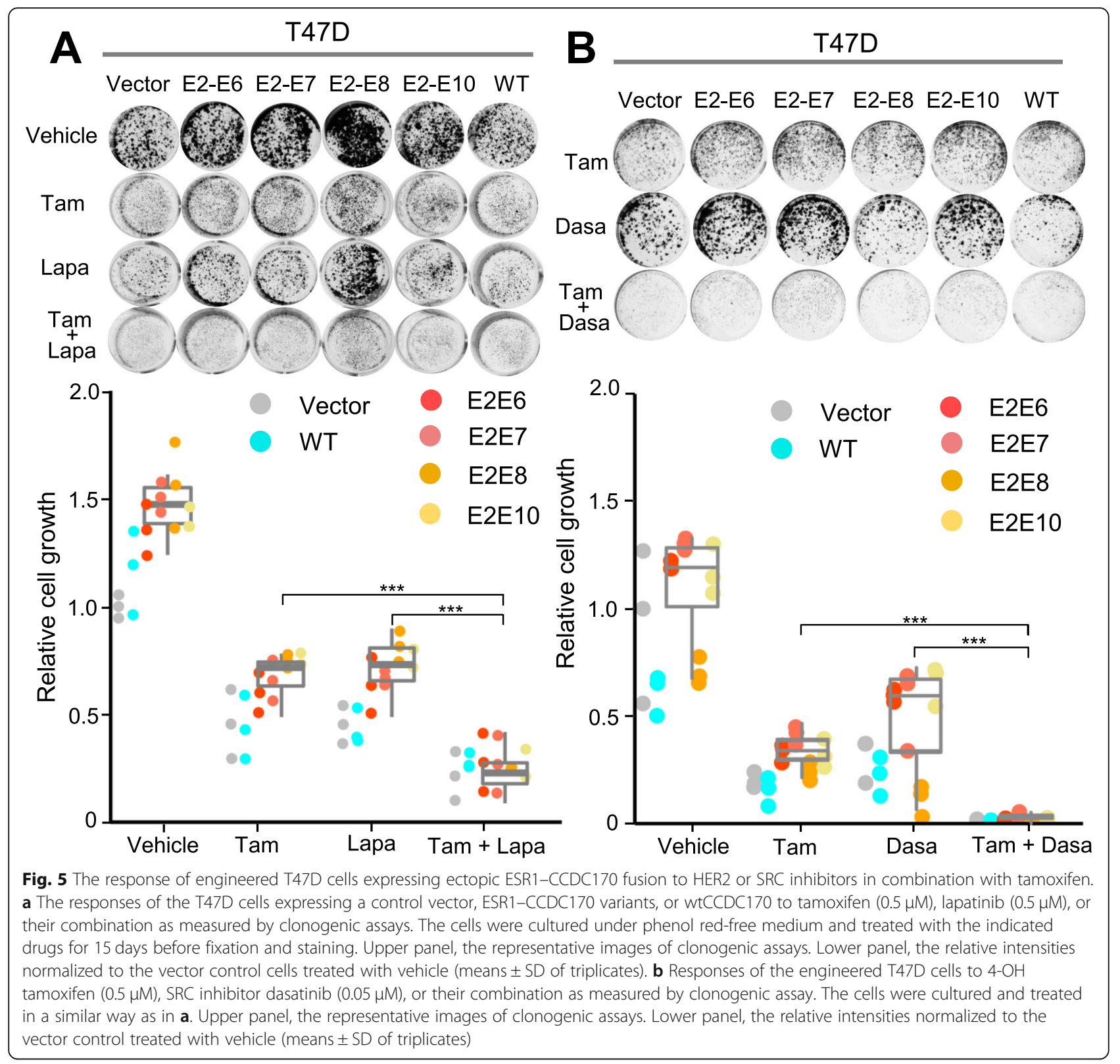

ESR1-CCDC170 positive breast tumors may depend on the context of HER2 and SRC expressions which calls for further studies to elucidate.

\section{Discussion}

Despite the tremendous success of endocrine therapies in $\mathrm{ER}^{+}$breast cancer, endocrine resistance is a common and major clinical challenge. In this study, we provide molecular evidence supporting the role of ESR1CCDC170 in breast cancer cell survival under endocrine therapy and the underlying mechanisms. Ectopic expression of the ESR1-CCDC170 fusion variants promote various levels of reduced endocrine sensitivities in the cell line and xenograft models. The relative tamoxifen resistance of ESR1-CCDC170 expressing xenograft tumors is similar to that of the xenograft tumors expressing ectopic ESR1 mutations previously reported [40]. ESR1 mutations that mutate its ligand binding domain constitute one of the most important driving mechanisms of endocrine resistance $[3,4,6]$, whereas the growth of the xenograft tumor models ectopically expressing ESR1 mutations can be effectively inhibited by endocrine treatment [40]. However, the relative endocrine resistance of the xenograft tumor models ectopically expressing ESR1 mutations was evident when the sizes of the different tumor models within the endocrine-treated group are compared, similar to our observations [40]. Mechanistic studies suggest that 


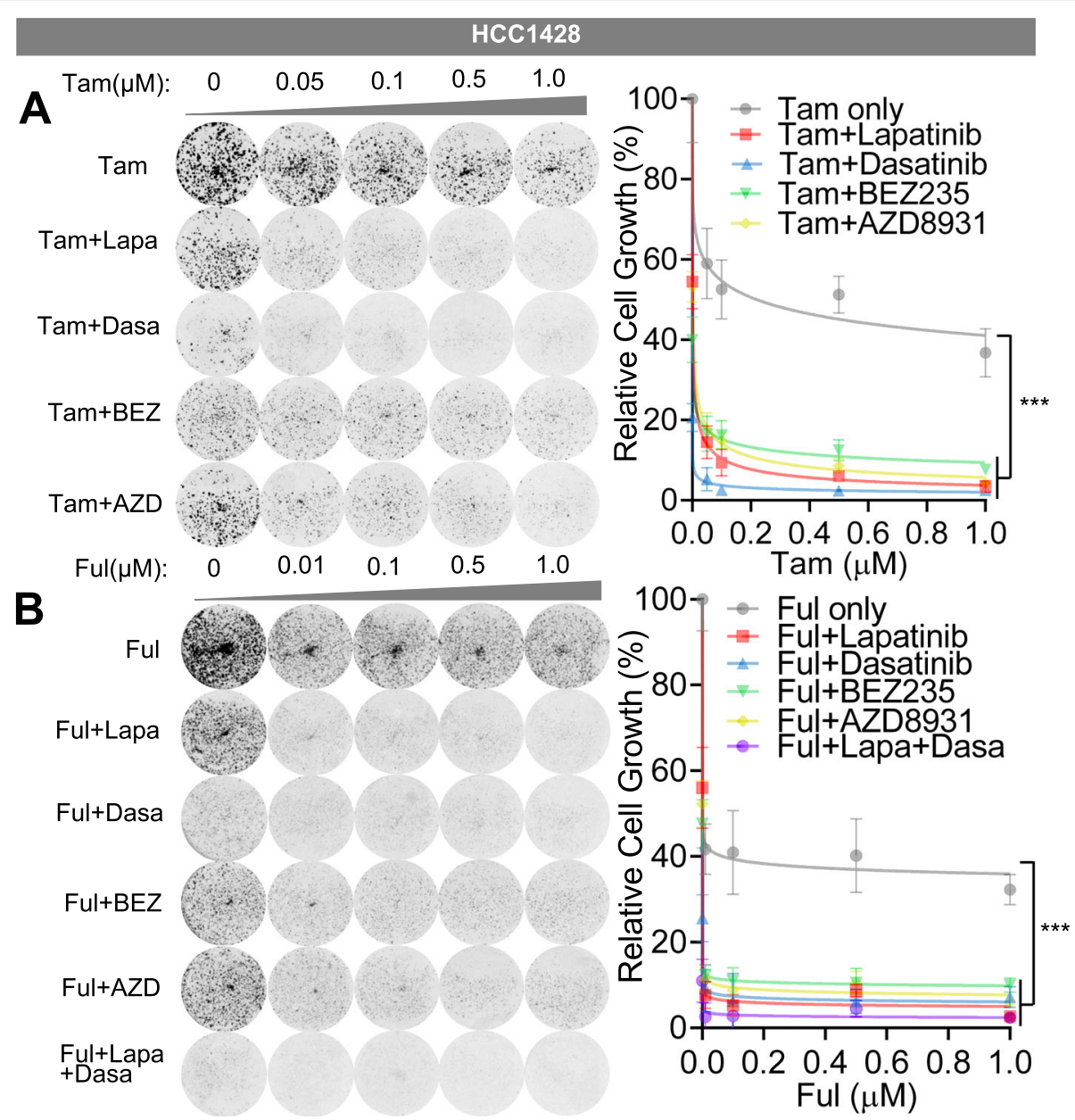

Fig. 6 SRC and HER2 inhibitors increase endocrine sensitivity of HCC1428 cells expressing endogenous ESR1-CCDC170 fusion. a Sensitivity of HCC 1428 cells to tamoxifen in combination with selective targeted agents as measured by clonogenic assays. HCC1428 cells were treated with different dosages of 4-OH tamoxifen $(\mu \mathrm{M})$, or 4-OH tamoxifen plus lapatinib $(2 \mu \mathrm{M})$, dasatinib $(0.05 \mu \mathrm{M})$, BEZ235 $(8 \mathrm{nM})$, or AZD8931 (1 uM). Data were normalized against vehicle treatment alone (as 100\%). b Sensitivity of HCC1428 cells to fulvestrant in combination with selective targeted agents as measured by clonogenic assays. HCC1428 cells were treated with different dosages of fulvestrant ( $\mu \mathrm{M})$, or fulvestrant plus lapatinib $(2 \mu \mathrm{M})$, dasatinib $(0.05 \mu \mathrm{M}), \mathrm{BEZ235}(8 \mathrm{nM})$, AZD8931 (1 uM), or lapatinib $(2 \mu \mathrm{M})+$ dasatinib $(0.05 \mu \mathrm{M})$. Data were normalized against vehicle treatment alone (as 100\%). Tam, 4-OH tamoxifen; Ful, fulvestrant, Lapa, lapatinib; Dasa, dasatinib, BEZ, BEZ235, AZD, ZAD8931. ${ }^{* * *} P<0.001$ (two-way ANOVA)

ESR1-CCDC170 fusions form complex with HER2/ HER3/SRC augment HER2/HER3 protein levels and signaling and enhance the activation of SRC/PI3K/AKT signaling under endocrine therapy in vitro and in vivo.

Overexpression or hyper-activation of the HER/SRC tyrosine receptor kinase family is known to contribute to endocrine resistance in breast cancer [2, 41-43]. HER2 and HER3 form heterodimer which is dependent on the HER3 ligand and is known to exert potent mitogenic signal [44]. HER2/HER3 heterodimer functions as a major oncogenic unit and is known to crosstalk with SRC and activates PI3K/AKT pathway to drive breast cancer $[36,45]$. SRC is broadly overexpressed in luminal breast cancer [46] and can crosstalk with HER2 when facilitated by other molecules such as CDCP1 [47]. As a result, SRC promotes the phosphorylation and activation of HER2, which in turn activates SRC [47]. Further, SRC activation has been reported to endow endocrine resistance through phosphorylating ER [31-33]. It is possible that the autonomous dimerization of ESR1-CCDC170 may help stabilize the interactions between HER2/ HER3/SRC tyrosine kinases and thus enhance their downstream signaling. Future studies will be required to pinpoint the precise mechanisms by which ESR1CCDC170 fusions regulate HER2/HER3/SRC signaling.

Wild-type CCDC170 contains a structural maintenance of chromosomes (SMC) domain (Additional file 1: Fig. S1). SMC proteins are formed by two long coiledcoil domains connected by a non-helical sequence called "hinge" which presumably corresponds to the low 


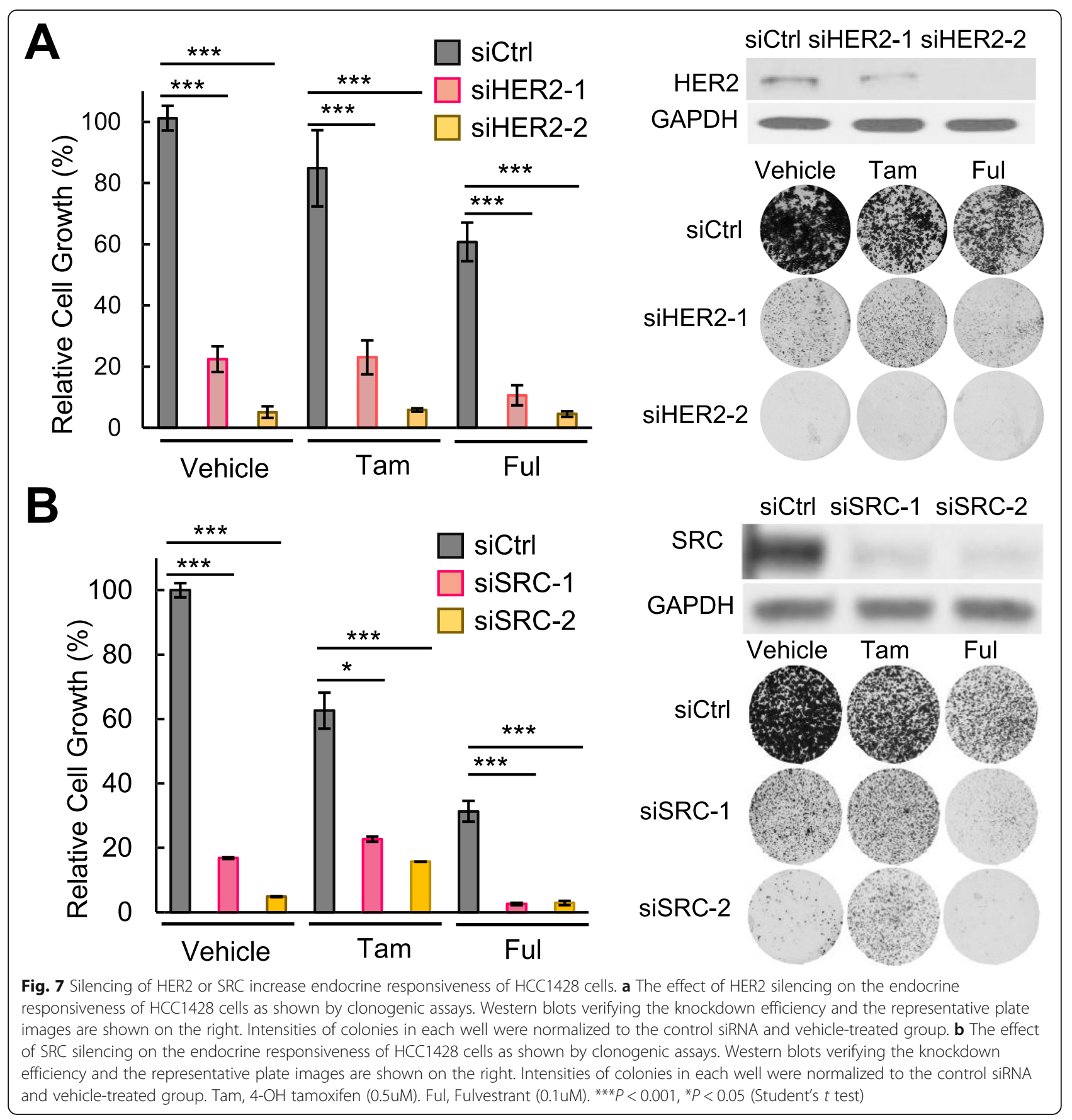

complexity region of CCDC170. The SMC proteins contain highly conserved ATP-binding cassette $(\mathrm{ABC})$ that drives its dimerization and fold back on themselves at the hinge region through antiparallel coiled-coil interactions [48]. The $\triangle C C D C 170$ proteins encoded by the ESR1-CCDC170 fusions have different degrees of deletion of the $\mathrm{N}$-terminal region of the SMC domain, but retain a putative high-affinity ATP-binding pocket at $\mathrm{C}$ terminus. The $\mathrm{N}$-terminal truncations of CCDC170 may expose the coiled-coil domain via reducing antiparallel coiled-coil interactions and thus alter its interactome, which calls for further investigations.

It should be stressed that while ESR1-CCDC170 functions through modulating SRC/HER2/HER3 complex, we cannot rule out the possibility that ESR1-CCDC170 could engage ER $\alpha$ to promote endocrine resistance. In fact, many survival signaling that drive endocrine resistance are known to act through phosphorylating and reactivating ER [31-33]. For example, SRC and AKT are known to phosphorylate Y537 and S167 respectively to 
modulate ER activity and endow endocrine resistance [31-33]. Thus, the survival signaling for endocrine resistance is not expected to act completely independent of ER. Future studies will be required to elucidate the function of ESR1-CCDC170 in modulating ER $\alpha$ activity under endocrine stress.

Furthermore, this study suggests a potential strategy to manage ESR1-CCDC170 positive patients via combining the HER2 inhibitor lapatinib and/or SRC inhibitor dasatinib with endocrine therapy. HER2 is amplified in approximately $10-15 \%$ of luminal breast cancer. While modest HER2 protein expression (IHC $1+$ or $2+$ ) can be detected in $60 \%$ of luminal breast cancer [49], HER2 inhibitors are generally not indicated in these tumors. While SRC has been reported to play a key role in breast cancer bone metastasis and hormonal therapy resistance [50-52], the clinical trials of SRC inhibitors in unselected metastatic breast cancer patients have been disappointing [50]. Our in vitro therapeutic studies on the T47D, HCC1428, and ZR-75-1 models suggest that the patients may be treated with HER2 and/or SRC inhibitors in combination with endocrine therapy depending on the context of HER2 and SRC expression levels. Since Her2 expression can be induced by endocrine treatment, but not SRC (Figs. 2c and 3a), the base-line expression of SRC could be particularly important for determining the therapeutic value of SRC inhibitor. Future preclinical and clinical studies are warranted to elucidate the optimal therapeutic strategy to manage ESR1-CCDC170positive patients in the clinical setting.

\section{Conclusions}

This study provides new molecular and functional evidence supporting the role of ESR1-CCDC170 in reducing endocrine responsiveness in breast cancer cells in vitro and in vivo and revealed a novel action mechanism that ESR1-CCDC170 binds to HER2/HER3/SRC complex and activates their downstream signaling to endow cancer cell survival under endocrine therapy. Our results also imply a potential therapeutic strategy to manage ESR1-CCDC170positive breast cancer patients via combining HER2 and/ or SRC inhibitors with endocrine therapy.

\section{Supplementary information}

Supplementary information accompanies this paper at https://doi.org/10. 1186/s13058-020-01325-3.

Additional file 1: Figure S1. Schematic of the ESR1-CCDC170 fusion variants and the encoded proteins.

Additional file 2: Figure S2. Verifying the ectopic expression of ESR1CCDC170 fusion protein products in engineered T47D cells lines by Western Blots.

Additional file 3: Figure S3. Verifying the efficiency of E2-E10 siRNA in HCC1428 cells and its effect on ESR1 and HER2 mRNA expression.
Additional file 4: Figure S4. Western blot analysis of protein extracts from the engineered T47D xenograft tumor tissues treated with tamoxifen shown in Fig. 1a.

Additional file 5: Figure S5. Ectopically expressed V5-tagged $\triangle C C D C 170$ co-precipitates with HER2.

Additional file 6: Figure S6. Subcellular localization of ESR1-CCDC170 and wtCCDC170 proteins in the engineered T47D cells.

Additional file 7: Figure S7. Western blots related to Fig. 4b.

Additional file 8: Figure S8. The effect of SRC and HER2 inhibitors on the endocrine response of ZR-75-1 cells expressing endogenous ESR1CCDC170 fusion.

Additional file 9: Figure S9. Western blots detecting HER2, HER3, and SRC protein expression in the cell models used in this study.

Additional file 10. The normalized RPPA data generated in this study.

\section{Abbreviations}

ABC: ATP-binding cassette; Als: Aromatase inhibitors; BiFC: Bimolecular fluorescence complementation; CCDC170: Coiled-coil domain containing 170; CSS: Charcoal-stripped serum; $\triangle$ CCDC170: Truncated CCDC170 proteins; E2: Estradiol; ER: Estrogen receptor; FDA: Food and Drug Administration; 4OHT: 4-Hydroxytamoxifen; ORF: Open reading frame; RPPA: Reverse phase protein array analysis; SERDs: Selective ER downregulators; SERMs: Selective ER modulators; siRNA: Small interfering RNA; SMC: Structural maintenance of chromosomes; TPER: Tissue Protein Extraction Reagent

\section{Acknowledgements}

We thank Dr. Shixia Huang, Hsin-Yi Cincy Lu, and Mr. Carlos Ramos from the Antibody-based Proteomics Core/Shared Resource for their excellent technical assistant in performing RPPA experiments. We thank Drs. Kimal Rajapakshe and Cristian Coarfa and Mr. Dimuthu Perera for RPPA data processing and normalization. We thank Suet Kee Loo for grammatical edits.

\section{Authors' contributions}

Li Li designed and performed cell biology and mechanistic experiments, analyzed the data, and wrote the manuscript. Ling Lin performed cell biology and mechanistic studies. J.V. performed the xenograft mouse and E2-E10 knockdown experiments. Y.H. performed fractionation assay and the BiFc experiments. X.W. performed the V5-IP experiments. S.L. analyzed the data. Y.T. generated the plasmid of the fusion variants. R.S. provided advices on the study and manuscript. X-S.W. conceived and supervised the study, analyzed the data, and wrote the manuscript. The authors read and approved the final manuscript.

\section{Funding}

This study is supported by NIH grant 1R01CA181368 (X-S.W.) 1R01CA183976 (X-S.W.), 1 R21 CA237964-01A1 (X-S. W.); Congressionally Directed Medical Research Program W81XWH-12-1-0166 (X-S.W.), W81XWH-12-1-0167 (R.S.), and CDMRP W81XWH-13-1-0431 (J.V.); Susan G. Komen foundation PDF15333523 (X.W.); and Nancy Owens foundation (X-S.W), as well as Commonwealth of PA Tobacco Phase 15 Formula Fund (X-S.W.), the Shear Family Foundation, and the Hillman Foundation. The RPPA experiment was supported in part by Cancer Prevention \& Research Institute of Texas Proteomics \& Metabolomics Core Facility Support Award (RP170005) and NCl Cancer Center Support Grant to Antibody-based Proteomics Core/Shared Resource (P30CA125123).

\section{Availability of data and materials}

All data generated or analyzed during this study are included in this published article and its supplementary information files.

\section{Ethics approval and consent to participate}

All animal experiments were performed in accordance with the institutional guidelines and regulations, and the animal protocol was approved by the BCM Institutional Animal Care and Use Committee (Approval \# AN-6123).

\section{Consent for publication} Not applicable. 


\section{Competing interests}

Dr. Rachel Schiff receives research funding from AstraZeneca, GlaxoSmithKline, Gilead Sciences, and PUMA Biotechnology, outside of this project, and is a consulting/advisory committee member for Macrogenics and, in the past, for Eli Lilly. The other coauthors do not have competing financial interests.

\section{Author details}

${ }^{1}$ Hillman Cancer Center, University of Pittsburgh, Pittsburgh, PA 15232, USA. ${ }^{2}$ Department of Pathology, University of Pittsburgh, Pittsburgh, PA 15261, USA. ${ }^{3}$ Women's Cancer Research Center, Magee-Womens Research Institute, Pittsburgh, PA 15213, USA. ${ }^{4}$ Department of Cell Biology, School of Basic Medical Sciences, Peking University Health Science Center, Beijing 100191, China. ${ }^{5}$ Lester \& Sue Smith Breast Center, Baylor College of Medicine, Houston, TX 77030, USA. ${ }^{6}$ Dan L. Duncan Cancer Center, Baylor College of Medicine, Houston, TX 77030, USA. ${ }^{7}$ Department of Medicine, Baylor College of Medicine, Houston, TX 77030, USA. ${ }^{8}$ Molecular \& Cellular Biology, Baylor College of Medicine, Houston, TX 77030, USA. ${ }^{9}$ Department of Biomedical Informatics, University of Pittsburgh, Pittsburgh, PA 15206, USA.

\section{Received: 15 October 2019 Accepted: 27 July 2020}

\section{Published online: 08 August 2020}

\section{References}

1. Patel HK, Bihani T. Selective estrogen receptor modulators (SERMs) and selective estrogen receptor degraders (SERDs) in cancer treatment. Pharmacol Ther. 2018;186:1-24.

2. Musgrove EA, Sutherland RL. Biological determinants of endocrine resistance in breast cancer. Nat Rev Cancer. 2009;9(9):631-43.

3. Ma CX, Reinert T, Chmielewska I, Ellis MJ. Mechanisms of aromatase inhibitor resistance. Nat Rev Cancer. 2015;15(5):261-75.

4. Jeselsohn R, Buchwalter G, De Angelis C, Brown M, Schiff R. ESR1 mutationsa mechanism for acquired endocrine resistance in breast cancer. Nat Rev Clin Oncol. 2015;12(10):573-83.

5. Hartmaier RJ, Trabucco SE, Priedigkeit N, Chung JH, Parachoniak CA, Vanden Borre P, Morley S, Rosenzweig M, Gay LM, Goldberg ME, et al. Recurrent hyperactive ESR1 fusion proteins in endocrine therapy-resistant breast cancer. Ann Oncol. 2018;29(4):872-80.

6. Lei JT, Gou X, Seker S, Ellis MJ. ESR1 alterations and metastasis in estrogen receptor positive breast cancer. J Cancer Metastasis Treat. 2019;5:38-53.

7. Mitelman F, Johansson B, Mertens F. The impact of translocations and gene fusions on cancer causation. Nat Rev Cancer. 2007;7(4):233-45.

8. Koivunen JP, Mermel C, Zejnullahu K, Murphy C, Lifshits E, Holmes AJ, Choi HG, Kim J, Chiang D, Thomas R, et al. EML4-ALK fusion gene and efficacy of an ALK kinase inhibitor in lung cancer. Clin Cancer Res. 2008;14(13):4275-83.

9. Singh D, Chan JM, Zoppoli P, Niola F, Sullivan R, Castano A, Liu EM, Reichel J, Porrati P, Pellegatta S, et al. Transforming fusions of FGFR and TACC genes in human glioblastoma. Science. 2012;337(6099):1231-5.

10. Laetsch TW, Hawkins DS. Larotrectinib for the treatment of TRK fusion solid tumors. Expert Rev Anticancer Ther. 2018;19(1):1-10.

11. Yersal O, Barutca S. Biological subtypes of breast cancer: prognostic and therapeutic implications. World J Clin Oncol. 2014;5(3):412-24.

12. Goksu SS, Tastekin D, Arslan D, Gunduz S, Tatli AM, Unal D, Salim D, Guler T, Coskun HS. Clinicopathologic features and molecular subtypes of breast cancer in young women (age </=35). Asian Pac J Cancer Prev. 2014;15(16): 6665-8.

13. Veeraraghavan J, Tan Y, Cao XX, Kim JA, Wang X, Chamness GC, Maiti SN, Cooper L, Edwards DP, Contreras A, et al. Recurrent ESR1-CCDC170 rearrangements in an aggressive subset of oestrogen receptor-positive breast cancers. Nat Commun. 2014;5:4577.

14. Schalbetter SA, Goloborodko A, Fudenberg G, Belton JM, Miles C, Yu M, Dekker J, Mirny L, Baxter J. SMC complexes differentially compact mitotic chromosomes according to genomic context. Nat Cell Biol. 2017;19(9):1071-80,

15. Laflamme G, Tremblay-Boudreault T, Roy MA, Andersen P, Bonneil E, Atchia K, Thibault P, D'Amours D, Kwok BH. Structural maintenance of chromosome (SMC) proteins link microtubule stability to genome integrity. J Biol Chem. 2014;289(40):27418-31.

16. Matissek KJ, Onozato ML, Sun S, Zheng Z, Schultz A, Lee J, Patel K, Jerevall PL, Saladi SV, Macleay A, et al. Expressed gene fusions as frequent drivers of poor outcomes in hormone receptor-positive breast cancer. Cancer Discov. 2018;8(3):336-53.
17. Giltnane JM, Hutchinson KE, Stricker TP, Formisano L, Young CD, Estrada MV Nixon MJ, Du L, Sanchez V, Ericsson PG, et al. Genomic profiling of ER(+) breast cancers after short-term estrogen suppression reveals alterations associated with endocrine resistance. Sci Transl Med. 2017;9,eaai7993:1-14.

18. Fimereli D, Fumagalli D, Brown D, Gacquer D, Rothe F, Salgado R, Larsimont D, Sotiriou C, Detours V. Genomic hotspots but few recurrent fusion genes in breast cancer. Genes Chromosomes Cancer. 2018;57(7):331-8.

19. Lei JT, Shao J, Zhang J, Iglesia M, Chan DW, Cao J, Anurag M, Singh P, He X, Kosaka Y, et al. Functional annotation of ESR1 gene fusions in estrogen receptor-positive breast cancer. Cell Rep. 2018;24(6):1434-44 e1437.

20. Yang SYC, Lheureux S, Karakasis K, Burnier JV, Bruce JP, Clouthier DL, Danesh A, Quevedo R, Dowar M, Hanna Y, et al. Landscape of genomic alterations in high-grade serous ovarian cancer from exceptional long- and short-term survivors. Genome Med. 2018;10(1):81.

21. Kim JA, Tan Y, Wang X, Cao X, Veeraraghavan J, Liang Y, Edwards DP, Huang S, Pan X, Li K, et al. Comprehensive functional analysis of the tousled-like kinase 2 frequently amplified in aggressive luminal breast cancers. Nat Commun. 2016;7:12991.

22. Yan $\mathrm{K}$, Li L, Wang $X$, Hong $R$, Zhang Y, Yang H, Lin M, Zhang S, He Q, Zheng $D$, et al. The deubiquitinating enzyme complex BRISC is required for proper mitotic spindle assembly in mammalian cells. J Cell Biol. 2015;210(2):209-24.

23. Basu D, Bewley AF, Sperny SM, Montone KT, Gimotty PA, Rasanen K, Facompre ND, Weinstein GS, Nakagawa H, Diehl JA, et al. EGFR inhibition promotes an aggressive invasion pattern mediated by mesenchymal-like tumor cells within squamous cell carcinomas. Mol Cancer Ther. 2013;12(10):2176-86.

24. Hai J, Zhu CQ, Wang T, Organ SL, Shepherd FA, Tsao MS. TRIM14 is a putative tumor suppressor and regulator of innate immune response in non-small cell lung cancer. Sci Rep. 2017;7:39692.

25. Schober P, Vetter TR. Repeated measures designs and analysis of longitudinal data: if at first you do not succeed-try, try again. Anesth Analg. 2018;127(2):569-75.

26. Morrison G, Fu X, Shea M, Nanda S, Giuliano M, Wang T, Klinowska T, Osborne CK, Rimawi MF, Schiff R. Therapeutic potential of the dual EGFR/ HER2 inhibitor AZD8931 in circumventing endocrine resistance. Breast Cancer Res Treat. 2014;144(2):263-72.

27. Gazdar AF, Kurvari V, Virmani A, Gollahon L, Sakaguchi M, Westerfield M, Kodagoda D, Stasny V, Cunningham HT, Wistuba II, et al. Characterization of paired tumor and non-tumor cell lines established from patients with breast cancer. Int J Cancer. 1998;78(6):766-74.

28. Moi LL, Flageng MH, Gjerde J, Madsen A, Rost TH, Gudbrandsen OA, Lien EA, Mellgren G. Steroid receptor coactivators, HER-2 and HER-3 expression is stimulated by tamoxifen treatment in DMBA-induced breast cancer. BMC Cancer. 2012;12:247.

29. Hossain Ml, Roulston CL, Kamaruddin MA, Chu PW, Ng DC, Dusting GJ, Bjorge JD, Williamson NA, Fujita DJ, Cheung SN, et al. A truncated fragment of Src protein kinase generated by calpain-mediated cleavage is a mediator of neuronal death in excitotoxicity. J Biol Chem. 2013;288(14):9696-709.

30. Storr SJ, Thompson N, Pu X, Zhang Y, Martin SG. Calpain in breast cancer: role in disease progression and treatment response. Pathobiology. 2015; 82(3-4):133-41.

31. de Leeuw R, Neefjes J, Michalides R. A role for estrogen receptor phosphorylation in the resistance to tamoxifen. Int J Breast Cancer. 2011;2011:232435.

32. Likhite VS, Stossi F, Kim K, Katzenellenbogen BS, Katzenellenbogen JA. Kinase-specific phosphorylation of the estrogen receptor changes receptor interactions with ligand, deoxyribonucleic acid, and coregulators associated with alterations in estrogen and tamoxifen activity. Mol Endocrinol. 2006; 20(12):3120-32.

33. Osborne CK, Schiff R. Mechanisms of endocrine resistance in breast cancer. Annu Rev Med. 2011;62:233-47.

34. Zheng ZY, Cheng CM, Fu XR, Chen LY, Xu L, Terrillon S, Wong ST, Bar-Sagi $D$, Songyang Z, Chang EC. CHMP6 and VPS4A mediate the recycling of Ras to the plasma membrane to promote growth factor signaling. Oncogene. 2012;31(43):4630-8.

35. Zheng ZY, Chang EC. A bimolecular fluorescent complementation screen reveals complex roles of endosomes in Ras-mediated signaling. Methods Enzymol. 2014;535:25-38.

36. Yarden Y, Pines G. The ERBB network: at last, cancer therapy meets systems biology. Nat Rev Cancer. 2012;12(8):553-63.

37. Schenone S, Brullo C, Musumeci F, Botta M. Novel dual Src/Abl inhibitors for hematologic and solid malignancies. Expert Opin Investig Drugs. 2010;19(8):931-45. 
38. Araujo J, Logothetis C. Dasatinib: a potent SRC inhibitor in clinical development for the treatment of solid tumors. Cancer Treat Rev. 2010; 36(6):492-500.

39. Engel LW, Young NA, Tralka TS, Lippman ME, O'Brien SJ, Joyce MJ. Establishment and characterization of three new continuous cell lines derived from human breast carcinomas. Cancer Res. 1978;38(10):3352-64.

40. Toy W, Weir H, Razavi P, Lawson M, Goeppert AU, Mazzola AM, Smith A, Wilson J, Morrow C, Wong WL, et al. Activating ESR1 mutations differentially affect the efficacy of ER antagonists. Cancer Discov. 2017;7(3):277-87.

41. Giuliano M, Trivedi MV, Schiff R. Bidirectional crosstalk between the estrogen receptor and human epidermal growth factor receptor 2 signaling pathways in breast cancer: molecular basis and clinical implications. Breast Care (Basel). 2013;8(4):256-62.

42. Massarweh S, Osborne CK, Creighton CJ, Qin L, Tsimelzon A, Huang S, Weiss $\mathrm{H}$, Rimawi M, Schiff R. Tamoxifen resistance in breast tumors is driven by growth factor receptor signaling with repression of classic estrogen receptor genomic function. Cancer Res. 2008;68(3):826-33.

43. Hiscox S, Jordan NJ, Morgan L, Green TP, Nicholson RI. Src kinase promotes adhesion-independent activation of FAK and enhances cellular migration in tamoxifen-resistant breast cancer cells. Clin Exp Metastasis. 2007;24(3):157-67.

44. Lee-Hoeflich ST, Crocker L, Yao E, Pham T, Munroe X, Hoeflich KP, Sliwkowski MX, Stern HM. A central role for HER3 in HER2-amplified breast cancer: implications for targeted therapy. Cancer Res. 2008;68(14):5878-87.

45. Holbro T, Beerli RR, Maurer F, Koziczak M, Barbas CF 3rd, Hynes NE. The ErbB2/ErbB3 heterodimer functions as an oncogenic unit: ErbB2 requires ErbB3 to drive breast tumor cell proliferation. Proc Natl Acad Sci U S A. 2003;100(15):8933-8.

46. Anbalagan M, Moroz K, Ali A, Carrier L, Glodowski S, Rowan BG. Subcellular localization of total and activated Src kinase in African American and Caucasian breast cancer. PLoS One. 2012;7(3):e33017.

47. Alajati A, Guccini I, Pinton S, Garcia-Escudero R, Bernasocchi T, Sarti M, Montani E, Rinaldi A, Montemurro F, Catapano C, et al. Interaction of CDCP1 with HER2 enhances HER2-driven tumorigenesis and promotes trastuzumab resistance in breast cancer. Cell Rep. 2015;11(4):564-76.

48. Hirano T. At the heart of the chromosome: SMC proteins in action. Nat Rev Mol Cell Biol. 2006;7(5):311-22.

49. Zhang H, Han M, Varma KR, Clark BZ, Bhargava R, Dabbs DJ. High fidelity of breast biomarker metrics: a 10-year experience in a single, large academic institution. Appl Immunohistochem Mol Morphol. 2018;26(10):697-700.

50. Kennedy LC, Gadi V. Dasatinib in breast cancer: Src-ing for response in all the wrong kinases. Ann Transl Med. 2018;6(Suppl 1):S60.

51. Vallabhaneni S, Nair BC, Cortez V, Challa R, Chakravarty D, Tekmal RR, Vadlamudi RK. Significance of ER-Src axis in hormonal therapy resistance. Breast Cancer Res Treat. 2011;130(2):377-85.

52. Zhang XH, Wang Q, Gerald W, Hudis CA, Norton L, Smid M, Foekens JA, Massague J. Latent bone metastasis in breast cancer tied to Src-dependent survival signals. Cancer Cell. 2009;16(1):67-78.

\section{Publisher's Note}

Springer Nature remains neutral with regard to jurisdictional claims in published maps and institutional affiliations.

Ready to submit your research? Choose BMC and benefit from:

- fast, convenient online submission

- thorough peer review by experienced researchers in your field

- rapid publication on acceptance

- support for research data, including large and complex data types

- gold Open Access which fosters wider collaboration and increased citations

- maximum visibility for your research: over $100 \mathrm{M}$ website views per year

At BMC, research is always in progress.

Learn more biomedcentral.com/submissions 